\title{
O Pensamento da Violência em Walter Benjamin e Jacques Derrida ${ }^{1}$
}

Idelber Avelar

Tulane University

Resumo: Este artigo examina o clássico ensaio de Walter Benjamin, Zur Kritik der Gewalt, à luz de um dos momentos importantes de sua fortuna crítica, o Force de loi, de

Jacques Derrida. Em primeiro lugar, questiono a associação que faz Derrida entre o ensaio de Benjamin e uma suposta "onda anti-parlamentar" no pensamento weimariano. Daí, passo a um exame da identificação feita por Derrida entre a noção benjaminiana de violência divina e o conceito de Destruktion que elaboraria Heidegger alguns anos depois. Para finalizar, tiro algumas conclusões acerca dos vínculos entre a leitura de Benjamin proposta em Force de loi e alguns postulados de outro ensaio de Derrida, "Interpretações em guerra", lido em Jerusalém, num colóquio realizado em 1988, durante a segunda Intifada, e marcado pela ausência de convidados palestinos.

Palavras-Chave: Violência. Benjamin, Walter. Derrida, Jacques. Heidegger, Martin. Palestina. Desconstrução.

\section{Preâmbulo}

Alguns meses antes da morte de Jacques Derrida, eu o contactara para dizer que havia preparado um texto com fortes restrições à leitura de Walter Benjamin proposta por ele em Força de lei. ${ }^{2}$ Ao compor o artigo, eu havia tentado me manter rigorosamente fiel às lições da desconstrução, experiência que permanece tão fundamental para mim hoje como na época dos meus primeiros contatos com os textos de Derrida, há vinte anos. Derrida, com a infinita generosidade e pródiga memória que lhe eram características, lembrava-se de um breve contato que havíamos tido em Duke University, pelos idos de 1995, e respondeu que estava ansioso para ler minhas críticas - que eu as mandasse logo que estivessem prontas. Na verdade, o texto em inglês já estava terminado, mas como o livro onde o artigo apareceria estava no prelo, decidi esperar um pouco mais para enviar- 
lhe a versão publicada, menos pela vaidade de ver o texto encadernado do que pelo desejo de escrever-lhe uma carinhosa dedicatória na primeira página. A espera foi fatal. O livro saiu, mas não a tempo de que eu o enviasse a Derrida. No segundo semestre de 2004, quando se publicava em inglês o livro que contém uma versão mais extensa deste artigo, ${ }^{3} \mathrm{eu}$, assim como toda a comunidade de leitores, alunos e admiradores de Derrida, recebemos o golpe violento (apesar de não inesperado) que foi a notícia de sua morte. $\mathrm{O}$ arrependimento de não lhe haver enviado a versão manuscrita do texto doeu fundo, porque algo me dizia que Derrida reconheceria que procedem pelo menos algumas das críticas aqui formuladas. Eis aqui, então, em português, o texto ao qual o destino não quis que Derrida tivesse acesso, e sobre o qual eu jamais saberei o que ele teria pensado. A ele, in memoriam, com a consciência de que a verdadeira desconstrução se dá sempre na alegria, mesmo enquanto nos enfrentamos à infinita tarefa do luto.

\section{Benjamin e a violência}

"Para a crítica da violência" 4 é um texto escrito por Walter Benjamin entre o fim de 1920 e o começo de 1921, aos 28 anos de idade, na esteira de seu compromisso com o movimento estudantil, sua revisão crítica do kantianismo e seu engajamento com a teoria da arte do romantismo alemão. ${ }^{5}$ Marcado pelo contato do autor com as Reflexões sobre a violência, de Georges Sorel, ${ }^{6}$ o texto benjaminiano procede por oposições, fazendo proliferar vertiginosamente as dicotomias. Elas se multiplicam, compondo um texto que avança quase que por cissiparidade. O texto inicia prometendo um exame da relação da violência com os campos da lei e da justiça. Obviamente, para Benjamin, estes não se confundem: "se a justiça é o critério dos fins, a legalidade é o critério dos meios". ${ }^{7}$ Aqui, o problema mais "elementar" seria o da diferença entre fins e meios. A esfera (Bereich) dos fins está excluída do estudo, diz Benjamin, já que o fundamental quando se discute o tema da violência é sua justificação como um meio. Primeira dicotomia, então: se a violência é um meio, impõe-se a pergunta sobre se, em cada caso, ela seria um meio para atingir fins justos ou injustos. Mas reduzir a pergunta a isto não ajuda a respondê-la, argumenta Benjamin, já que aí a reflexão sobre a violência se reduziria a um critério para 
os casos de seus usos. Tudo, em outras palavras, se esgotaria no juízo sobre os fins. Um critério mais exato é necessário, diz Benjamin, para discriminar entre os próprios meios.

A ausência de um critério para pensar os meios seria um dos pecados de uma corrente da filosofia legal: o direito natural, para o qual a violência é um produto da natureza, só condenável se usada para fins injustos. O beco sem saída oposto e simétrico acossaria a corrente antagônica, o direito positivo, que só pode pensar a legalidade dos meios, não a justiça dos fins. Se o direito natural tenta, "pela justiça dos fins, 'justificar' os meios, o direito positivo tenta 'garantir' a justiça dos fins pela justificação dos meios" ${ }^{8}$ Uma corrente parte da premissa da naturalidade da violência e, a partir dessa premissa, reduz a justificação dos meios à justiça dos fins. Reduz o justo ao ajustado. A outra corrente se dedica puramente a julgar a justificação dos meios e avaliá-los dentro de fins cuja justiça está constituída de antemão. Reduz o justo ao legal. "Se o direito positivo é cego à incondicionalidade [Unbedingtheit] dos fins, o direito natural é cego à contingência [Bedingtheit] dos meios". 9 A tarefa da crítica é encontrar, então, um "ponto de vista exterior à filosofia legal positiva mas também ao direito natural" (181-2). ${ }^{10}$ Para construir esse ponto de vista, Benjamin recorda os usos legais da violência, incluindo-se aí os momentos em que o Estado renuncia, parcialmente, ao seu monopólio sobre o uso legal da violência. Um desses casos é o direito à greve.

O que é uma greve? Pode-se dizer que a recusa ao trabalho é um ato de violência? Sem dúvida, propõe Benjamin, desde que a leiamos do ponto de vista daqueles que recorrem a ela. Há uma relação antitética entre a leitura do Estado, que permite a greve mas mantém o poder de declará-la ilegal, e a leitura dos que recorrem à greve, que não podem senão vê-la como "o direito ao uso da violência/força [Gewalt $]$ para atingir certos fins". ${ }^{11}$ Na paráfrase que faz Derrida de todo o texto benjaminiano, falta essa explicitação de como a greve, em Benjamin, é violência e não-violência ao mesmo tempo. Aí está a impossibilidade de uma língua que nomeie a violência já do próprio ato de greve. A greve será sempre lida das duas maneiras simultaneamente, antes da distinção entre a violência implícita ou potencial do ato de greve e a violência explícita da greve geral revolucionária (dicotomia que, bem vê Derrida, não é pura, facilmente separável etc.). Primeira redução da paráfrase de Derrida, então: desaparece a fratura interna própria ao 
conceito de violência de Benjamin, fratura emblematizada no momento em que o direito de greve se torna práxis.

Lida do ponto de vista do trabalhador, a greve é já, desde sempre, violência. A omissão desse momento de cisão constitutiva no texto de Benjamin não é, em Força de $l e i$, de Derrida, uma omissão entre outras. De alguma maneira permite - aqui já vamos adiantando a hipótese - a aproximação com Heidegger e a caracterização de "Para a crítica da violência" como um texto "demasiado heideggeriano". ${ }^{12}$ Já veremos o que poderia significar "heideggeriano" nesses contextos (o do ensaio de Benjamin em 1921, 5 anos antes da publicação de Ser e tempo e 18 anos antes do começo da Segunda Guerra, e o do texto de Derrida, 1989, dois anos depois do começo da Intifada contra a ocupação israelense). Em todo caso, ao parafrasear essa passagem, Derrida insiste que não se pode fazer uma clara separação entre a greve e a greve geral revolucionária, como se este fosse um dado que o texto benjaminiano omitisse. Insiste nesse ponto enquanto omite o antagonismo que torna inevitável a inseparabilidade dos dois em Benjamin: o caráter da greve como, desde sempre, violência e não-violência, irredutivelmente as duas coisas ao mesmo tempo, dependendo do lugar de leitura social.

O próximo corte em "Para a crítica da violência" é a separação entre a violência preservadora do direito [die rechtserhaltende Gewalt] e a violência fundadora do direito [die rechtsetzende Gewalt]. Contra esse ato que o Estado não caracteriza como inicialmente violento, a greve, mas que para o trabalhador é desde sempre um ato de violência, o Estado pode lançar mão da violência legalizada como instrumento preservador da lei. Há, por um lado, a cisão entre a violência revolucionária, fundadora de outro direito, e a violência preservadora do direito, que opera dentro da legalidade existente. Há, por outro lado, o corte que tem lugar na própria condição de possibilidade da violência, sua caracterização ao mesmo tempo como violência, quando lida do ponto de vista do trabalhador, e não violência, quando lida do ponto de vista do Estado. Seu nascimento é cindido entre o ser e o não ser. Em outras palavras, há, por um lado, a dicotomia entre a violência-origem-do-direito e a violência-modo-de-reproduçãocotidiana-do-direito. Mas essa dicotomia (impura e instável) torna-se possível pelo caráter inerentemente cindido, duplo da própria violência, no momento de sua emergência. Derrida, em sua análise, escolhe enfatizar a dicotomia derivada (a que separa 
duas formas de violência) e termina obviando à dicotomia fundante (não a que separa distintas formas de violência, mas a que cinde a violência mesma, no momento de sua constituição).

Mesmo que impura e instável, mesmo que sujeita a contaminações mútuas, a separação entre a violência fundadora do direito e a violência preservadora do direito é incontornável no pensamento de Benjamin. Como nota Derrida, essa dicotomia não se confunde com a diferença entre a violência da greve (para o trabalhador) e a violência (episódica, ocasional, mas sempre possível) do Estado contra a greve, para defender a legalidade existente. Se é certo que o Estado, quando intervém, o faz para manter uma lei, não é certo que a violência da greve tenha necessariamente a meta de instalar outra lei. Não, pelo menos, até que se transforme em greve geral revolucionária. Posto que a greve, em si mesma, não é vista pelo patrão como um ato de violência, por que o Estado recorreria à violência explícita contra ela? Pelo medo, diz Benjamin, de que a greve se converta em greve geral revolucionária, instaladora de outra legalidade. A violência preservadora do direito não pode operar, então, senão como antecipação de uma violência virtual, possível, futura, que viria a derrotá-la e instalar outra legalidade. Não há qualquer razão essencial para apostar que a violência da greve se transformará em violência fundadora de outro direito; mas a manutenção da lei não pode se arriscar. Lança mão, de antemão, da violência.

Mas seria a violência revolucionária sempre equivalente à violência fundadora de direito? Seria a rechtsetzende Gewalt sempre revolucionária? Não, diz Benjamin, e isso é demonstrável ao examinarmos uma violência que não é um exemplo entre outros: a violência militar. Por um lado, o militarismo é a subordinação dos cidadãos à lei; entra para manter uma legalidade existente. Por outro lado, "o militarismo é a compulsão [Zwang] ao uso universal da violência como meio para fins do Estado", ${ }^{13}$ fins que incluem a construção de novas legalidades. Daí a existência de algo inerentemente fundador de direito na violência militar. $\mathrm{O}$ exemplo privilegiado da inseparabilidade entre as violências preservadora e fundadora do direito, para Benjamin, seria a violência militar. Este fato é significativo e tem conseqüências importantes.

Quando, em sistemas legais primitivos, se estabelece a pena de morte para crimes contra a propriedade, não se trata ali de um mero preservar a lei. Trata-se de impor outra 
lei. O exemplo privilegiado do momento fundador de lei da violência militar é a promulgação da pena de morte para crimes contra a propriedade. Para Benjamin, o momento da rasura do limite entre a violência da preservação e a da fundação do direito é a entrada da pena de morte para punir o ataque à propriedade. Essa instalação revelaria "algo podre" [etwas Morsches] na lei. Assim como a possível greve geral revolucionária é fundadora de lei, também o é, para Benjamin, a violência militar, alegorizada na violência que mata legalmente ao punir crimes contra a propriedade, tal punição representando o momento em que essa violência se converte em legalidade. A instalação da pena de morte para crimes contra a propriedade seria aqui a alegoria da fundação do direito. Isso significa que uma vez instalada essa punição no aparato estatal, toda violência legal ocorrerá com fins de preservar a lei? E que toda instalação de uma nova legalidade virá de forças revolucionárias, de possíveis greves gerais? De nenhuma maneira, responde Benjamin. O Estado desenvolveu um aparato onde se suspende a diferença entre as violências fundadora e preservadora de lei. Dentro da própria legalidade há um aparato que não só mantém, mas que cria a legalidade: a polícia. Se a violência fundadora de um novo direito tem que provar o seu valor como força vitoriosa, e a violência preservadora do direito está sujeita à restrição de que ela deve servir a fins constituídos de antemão, ou seja, não pode se colocar novos fins, a violência policial está, para Benjamin, "emancipada de ambas condições". ${ }^{14} \mathrm{Nem}$ tem que provar seu valor enquanto força vitoriosa, nem tampouco tem que se resignar a operar dentro da legalidade existente. Em incontáveis casos a polícia intervém "por razões de segurança" [Sicherheit wegen] em contextos onde "não há tal situação legal clara". ${ }^{15}$ Tais casos são tão incontáveis que definem a essência da violência policial, se é que esta possui uma essência - Benjamin define-a como "sem forma [gestaltlos] . . . em nenhum lugar tangível, pervasiva, espectral [gespenstlische]", ${ }^{16}$ ou seja, ele a define de maneira notavelmente semelhante ao espectro teorizado por Derrida em Espectros de Marx. ${ }^{17}$

Se a policia usa a violência para fins legais, ela o faz com a autoridade simultânea de decidir a natureza destes fins. Em todo caso, para Benjamin, a polícia seria a violência legalizada que, no entanto, não está circunscrita dentro de qualquer direito. É a voz da lei, mas não se deixa circunscrever por ela. Tem por função manter a lei, mas o faz, "em incontáveis casos", fora da lei existente, instalando outra lei. Certamente, para Benjamin, 
não se pode diferenciar nitidamente os dois tipos de violência: o aparato encarregado de fazê-lo não pode senão violar constantemente esses limites, não pode senão operar fora da lei. A manutenção da lei é seu exterior. A manutenção da lei, por definição, recorre a um lá-fora com respeito à lei. A manutenção da lei é por definição ilegal. Não só injusta, mas também ilegal.

Para Benjamin, a decadência de uma instituição ocorreria quando ela se esquece da violência que the deu origem. Este seria o caso do parlamento. O parlamento, segundo Benjamin, não permaneceu consciente das forças revolucionárias às quais deve sua existência. Parafraseando esse trecho, Derrida fala do texto de Benjamin como partícipe de uma "grande onda [vague] anti-parlamentar e anti-Aufklärung". ${ }^{18}$ "Para a crítica da violência" se alinha, nos parece, com algo que nunca pôde ser onda, e que se manteve como uma tradição subterrânea: a tradição da crítica do esquecimento. A declaração acerca do caráter amnésico do parlamento não é redutível a uma suposta posição "antiparlamentar" de Benjamin que, afinal de contas, reconhece que o florescimento do parlamento pode ser "desejável e gratificante". Não se trata de um ataque ao parlamento e sim, para simplificar ao máximo, de um lembrete: é uma ingenuidade acreditar que o parlamento é a antitese da violência. Não se pode jamais associá-lo ao lugar da nãoviolência, já que ele é, por definição, o espaço de esquecimento da violência - e portanto, para um Benjamin que já conhecia Freud, lugar de uma violência muito particular: a repressão neurótica da memória da violência.

Chegamos ao momento do ensaio de Benjamin em que se coloca a pergunta: "será possível alguma resolução não violenta dos conflitos?" 19 A resposta de Benjamin é paradoxal. Sim, com certeza. As relações pessoais nos mostram uma variedade de exemplos. A diferença, assinala Benjamin, é que nas relações pessoais a opção pela não violência vem do medo das desvantagens mútuas que surgiriam do confronto violento. Nos conflitos políticos a regra é que não sejam de antemão visíveis, aos atores sociais, os efeitos da violência que se abateriam tanto sobre os vencedores como sobre os vencidos. O paradoxo se manifesta quando Benjamin tenta localizar, no terreno social, qual seria o equivalente das relações pacíficas entre os indivíduos. Para responder essa pergunta, Benjamin recorre a outra dicotomia, já não entre a violência da greve e a violência antigreve do Estado, e sim a violência de dois tipos de greve, dicotomia que Benjamin herda 
de Georges Sorel. Esses dois tipos seriam a greve política e a greve proletária geral. A greve política, depois do ganho material, da transformação das condições materiais dos trabalhadores, coloca sobre a mesa a questão da volta ao trabalho. A greve proletária geral, a que destrói o poder do Estado, se instala fora de toda legalidade. Ao contrário da greve política, ela se coloca a tarefa de destruir todo o poder estatal. Aqui entra o comentário paradoxal de Benjamin: a greve geral revolucionária seria, pelo próprio fato de não propor outra legalidade, e sim de destruir a legalidade, a greve verdadeiramente não violenta. Quanto mais geral e revolucionária, menos violenta. Em outras palavras, a noção de revolução, de destruição do aparato estatal não é associada, em Benjamin, à violência, e sim ao momento utópico da não violência.

Conclusão de Benjamin: a resolução não violenta dos conflitos só é possível na medida em que não se exclua, de antemão, a violência. Para esclarecer esse paradoxo ele volta à dicotomia estabelecida no princípio do ensaio, entre o direito natural e o direito positivo. Deixamos essa distinção no momento em que estabelecemos que enquanto o direito natural tenta, pela justiça dos fins, justificar os meios, "o direito positivo tenta 'garantir' a justiça dos fins pela justificação dos meios". O direito natural reduz o justo ao ajustado, confunde a justiça com a necessidade. O direito positivo reduz o justo ao legal, confunde justiça com a lei. Ambos mantêm a referência a uma relação supostamente necessária entre o justo dos fins e o justificado dos meios. O que aconteceria se vislumbrássemos uma violência que, usando meios justificados, estivesse em conflito irreconciliável com a justiça dos fins? Ou que surgisse uma violência que já não fosse um meio para um certo fim, e sim algo absolutamente diferente, ainda não pensado? Em outras palavras, o que aconteceria com uma violência irredutível à dialética entre fins e meios?

Para tentar definir esse lugar indizível, Benjamin recorre a um adjetivo que freqüentemente aparece em sua obra inicial como nome do inomeável: a violência completamente alheia à dialética entre fins e meios seria, ao contrário da violência legal que Benjamin chama mítica, uma violência divina. Diz Benjamin: "se a violência mítica é fundadora do direito, a violência divina é destruidora de todo direito". ${ }^{20}$ A violência divina seria, para Benjamin, "aniquiladora". Só a banalidade da violência mítica, diz Benjamin, é reconhecível cotidianamente pelos homens. A violência mítica, fundadora do 
direito, seria, para Benjamin, perniciosa, assim como é perniciosa a violência administrativa, preservadora do direito que lhe serve. "À violência divina poderíamos chamar violência soberana", waltende, quase um homófono de Walter, nome de batismo de Benjamin, belo fechamento do ensaio de Benjamin, e ponto de partida do Força de lei, de Derrida.

Ao parafrasear esse trecho Derrida diz o seguinte: "depois há a distinção entre a violência fundadora do direito, dita 'mítica' (subentendido: grega, me parece) e a violência destruidora da direito, dita 'divina' (subentendido: judaica, me parece)". ${ }^{21}$ Derrida acrescenta um "me parece" quase que como uma denegação: as palavras "grega" e "judaica" não aparecem no ensaio de Benjamin no contexto da distinção entre violência mítica e violência divina, ou em qualquer outro contexto. É verdade que Benjamin remete a violência mítica ao relato de Niobe e a violência divina a uma leitura do quinto mandamento da Bíblia. Mas a conversão desses relatos em atributos, adjetivos nacionais, é uma operação que realiza o texto derridiano - reconhecendo, além do mais, que o faz, com o curioso "me parece". Ela não é parte do texto de Benjamin.

$\mathrm{O}$ que significa aqui reduzir dois relatos singulares à condição de alegorias nacionais? A segunda parte de Força de lei, que lida com o texto benjaminiano, é apresentada na Universidade de Califórnia em Los Angeles, em 1990, num colóquio intitulado "O nazismo e a solução final". O colóquio é sobre a solução final, mas Derrida lê o texto de Benjamin, de 1921: "O que teria pensado Benjamin, ou pelo menos qual pensamento de Benjamin está virtualmente formado ou articulado nesse ensaio (e é antecipável?) sobre o tema da solução final?". ${ }^{22}$ Confesso que foi a primeira e única vez que encontrei, num ensaio de Derrida, esta construção condicional proléptica: o que teria pensado X de Z? O que diz, prolepticamente, este texto, sobre esse outro fenômeno, vinte anos posterior? A pergunta que guia o texto de Derrida é externa ao texto de Benjamin; ela é movida diretamente pelo seu marco de apresentação. Isto vindo, claro, do pensador que mais nos ensinou, nos últimos quarenta anos, a formular perguntas rigorosamente internas aos textos que lemos.

Para introduzir essa pergunta, Derrida oferece uma caracterização do ensaio de Benjamin como texto que teria pertencido a uma "onda anti-parlamentar e antiAufklärung sobre a qual o Nazismo terá subido à superfície e "surfado". ${ }^{23}$ Mas no ensaio 
de Benjamin não há menção à Ilustração, e uma análise rigorosa tornaria muito problemática, no melhor dos casos, sua caracterização como texto anti-Ilustração - tratase de um texto que oferece marteladas de razão crítica ao mítico tema da violência. A menção de Benjamin ao parlamento, como vimos, se dá num contexto de crítica do esquecimento da instituição parlamentar com respeito à violência que a funda, e em nenhum momento se deixa caracterizar como simplesmente "anti-parlamentar". Todo o contrário: o texto é uma intervenção contra o esquecimento no parlamento. Derrida parece igualar a crítica do esquecimento na instituição, a crítica da instituição enquanto esquecimento, a uma simples corroboração da violência anti-parlamentar.

Derrida abre o texto justificando a leitura do ensaio de Benjamin no contexto do colóquio:

Este texto inquieto, enigmático, terrivelmente equívoco, acredito eu, está de antemão (mas pode se dizer aqui "de antemão"?) assombrado pelo tema da destruição radical, da exterminação, da aniquilação total, e em primeiro lugar a aniquilação do direito, senão da justiça; e entre esses direitos, os direitos humanos (droits de l'homme), pelo menos tal como estes podem ser interpretados dentro de uma tradição jusnaturalista do tipo grego ou do tipo "Aufklärung". De propósito digo que este texto está assombrado pelos temas da violência exterminadora ... ${ }^{24}$

Interessa-nos aqui a confusão entre aniquilação e violência no vínculo entre a primeira e a segunda frases. O texto de Benjamin sim, se articula a partir da revolução como aniquilação de toda lei (e neste sentido o texto fala de destruição), mas como vimos, esse momento para Benjamin (o fim de toda lei) é o momento utópico da não violência, momento análogo ao que o próprio Derrida, em outras obras, chamaria de "promessa" ou “dom”. Em Benjamin opera um axioma: quanto mais revolução, menos violência. Na leitura que faz Derrida em Força de lei opera uma associação de idéias entre revolução e violência que mascara o caráter inerentemente cindido desta última no ensaio de Benjamin. Ao comentar o momento da destruição em Benjamin (que nesse ensaio é sempre co-extensivo à destruição da lei, do Estado), Derrida acrescenta um "senão a aniquilação da justiça" como possível tema do texto - texto que trata, como vimos, da aniquilação da lei. Seria impossível perguntar se para Benjamin a aniquilação de lei poderia disseminar-se a ponto de ameaçar a própria justiça, como o faz Derrida; esta 
pergunta é impensável em Benjamin porque para este a promessa de justiça implica a destruição da lei, destruição que, recordemos, não é um sinônimo de violência, e sim o contrário: é o signo da própria possibilidade da não violência, na medida em que ela se encarne numa revolução genuína. Quanto mais revolucionária, mais desprovida de violência.

A caracterização do ensaio de Benjamin nesse marco se instala através da referência a outro texto de Derrida, onde as alegorizações nacionais dos relatos se anunciam no próprio título: "Interpretations at War: Kant, o judeu, e o alemão", ${ }^{25}$ apresentado em Jerusalém em 1988, durante a primeira Intifada contra a ocupação israelense. O resumo do argumento, distribuído antes da palestra, se intitula "A psique judaico-alemã: os exemplos de Hermann Cohen e Franz Rosenzweig”. Trata-se de uma leitura de dois pensadores judeus não sionistas, sendo que Rosenzweig, inclusive, era hostil ao projeto de um estado israelense. Para as várias mesas do congresso não se convidou nenhum palestino. Derrida menciona o fato na introdução de sua fala, manifesta sua "preocupação" ante os organizadores, Wolfgang Iser e Sanford Budick, condena as "violências" do terrorismo e das forças policiais e reafirma sua amizade a palestinos e israelenses. As questionáveis comparabilidade e isomorfia entre a violência terrorista desesperada e os metódicos massacres do exército de ocupação, na introdução de Derrida, não são alheias às distorções que sofreria o ensaio de Benjamin em suas mãos. Também em "Interpretações em guerra" Derrida fala de seus objetos de análise (Cohen e Rosenzweig) como "antecipadores de Heidegger" ou do que "alguns descreveram como o encontro com o magistério de Heidegger durante os anos imediatamente posteriores à guerra". As leituras que se seguem, iluminadoras da obra de Rosenzweig e Cohen, não dispensam com a pergunta inicial que os estabelece como "antecipadores de Heidegger", em todo caso antecipadores de uma temática que amadureceria e floresceria com a obra que Heidegger escreveria nos anos 20. A estrutura da pergunta, de novo, é proléptica, teleológica e privilegia uma lente heideggeriana.

Em ambos os ensaios a referência a Heidegger confere o eixo central ao postulado de uma "psique" que Derrida nomeia “judaico-alemã". Cohen, Rosenzweig, Scholem, Adorno, Arendt e Benjamin, são todos eles lidos, de alguma maneira, a partir de Heidegger e a partir da ausência de outro elemento, quiçá alegorizável na figura do 
palestino ausente do congresso de Jerusalém no qual fala Derrida. Em Força de lei tratase de "certas afinidades, limitadas mas determináveis entre o texto de Benjamin e certos textos de Carl Schmitt, e mesmo de Heidegger" ${ }^{26}$ Entre tais afinidades Derrida contaria "a hostilidade à democracia parlamentar, mesmo à democracia enquanto tal, não só em razão da hostilidade à Aufklärung, de uma certa interpretação do polemos, da guerra, da violência e da linguagem". ${ }^{27}$ Mesmo fazendo a óbvia ressalva de que a Destruktion heideggeriana não pode ser confundida com o "conceito de 'destruição' que também se encontrava no centro do pensamento benjaminiano", ${ }^{28}$ Derrida propõe "perguntar-se o que significa, o que prepara ou antecipa entre as duas guerras uma temática tão obsessiva". ${ }^{29}$

A referência à temática da destruição em Benjamin como uma obsessão é curiosa, já que sem dúvida trata-se de uma noção que está bem longe de ser ubíqua em Benjamin. A noção de destruição entra no ensaio para nomear o momento da violência divina, "soberana", waltende, ou seja, a violência que realiza uma destruição muito particular, a da lei. Em outras palavras não há, em Benjamin, uma associação entre violência e destruição, pelo menos nunca se reduz aquela à ação desta. Por outro lado essa "obsessão", para Derrida, "antecipa" ou "prepara" algo entre as guerras. Este algo se deixaria ler, supõe-se. Deixar-se-ia nomear: por que não chamá-lo pelo nome, o Nazismo, eufemizado por Derrida "como aquilo que se prepara entre as duas guerras". Buscar-se-ia então aquilo que, no texto de Benjamin de 1921, antecipa ou prepara a resposta que a própria formulação demanda, ou seja, o Nazismo, ou como prefere Derrida, a "onda sobre a qual o Nazismo subiu à superfície e surfou". Eis aqui o exemplo claro de uma interrogação a um texto que não obedece às rigorosas e necessárias pautas éticas formuladas pelo próprio Derrida, em "Para uma ética da discussão", a última réplica a Searle. ${ }^{30}$

Determinado por essa pergunta proléptica exterior ao texto, Derrida passa a uma conclusão em forma de uma interrogação que nos parece monstruosa. Valha a extensa citação, a partir da qual faremos um comentário final.

[Benjamin] provavelmente teria tomado a solução final como a conseqüência extrema de uma lógica do Nazismo que . . . teria correspondido a uma radicalização múltipla: 
1. a radicalização do mal vinculado à queda na linguagem da comunicação, da representação, da informação [...]

2. a radicalização totalitária de uma lógica do Estado [...]

3. a corrupção radical mas também fatal da democracia parlamentar e representativa por uma polícia moderna que é inseparável dela $[\ldots]$

4. uma radicalização e uma extensão total do mítico, da violência mítica. $^{31}$

Omitamos, por incontáveis, as razões que levaram Benjamin a não pensar o Nazismo como nenhuma dessas coisas. Do ponto de vista benjaminiano, por certo, o Nazismo jamais equivaleria à violência mítica, ou ao mítico enquanto tal, nem muito menos a uma corrupção da democracia pela força policial. O que pensou Benjamin sobre o Nazismo está dito e explícito para quem quiser ler, em vários lugares, mas muito especialmente em seu testamentário "Sobre o conceito de história", texto omitido por Derrida num ensaio de oitenta páginas sobre o espaço no qual Benjamin "teria armado" seu discurso sobre o Nazismo e a solução final. Não se trata de cobrar que Derrida lesse outro texto, mas especular sobre o que Benjamin "teria pensado" sobre o Nazismo sem referir esse texto me parece bastante grave.

O fechamento do texto de Derrida se ancora na especulação:

Benjamin teria quiçá julgado vão e sem pertinência, em todo caso sem uma pertinência comensurável com o evento, todo processo jurídico do Nazismo e de suas responsabilidades, todo aparato de julgamento, toda historiografia ainda homogênea com o espaço no qual o Nazismo se desenvolveu, até e a solução final. ${ }^{32}$

Essa especulação é literalmente irremissível a qualquer texto assinado por Benjamin, antes de 1921 ou depois. O que, na obra de Benjamin, autorizaria a percepção de que ele teria achado "vão e sem pertinência" um julgamento jurídico do nazismo? Depois dessa escandalosa suposição, Derrida afirma que "esse texto, como muitos outros de Benjamin, é ainda demasiado heideggeriano, demasiado messiânico-marxista ou arqueoescatológico para mim". ${ }^{33}$ Tratar-se-ia, para Derrida, de "julgar a possível cumplicidade entre todos esses discursos e o pior (aqui a "solução final')". Essa "possível cumplicidade" é um fantasma possibilitado pela leitura retrospectiva do texto benjaminino a partir do tema da solução final, posterior a ele em 20 anos. Para Derrida, 
isso definiria uma "tarefa e uma responsabilidade cujo tema eu não fui capaz de ler nem na "destruição" benjaminiana nem na Destruktion heideggeriana" ${ }^{34}$ Reveladoramente, ao conceito heideggeriano, Derrida concede a nobreza da citação na língua original.

Fechamento apropriado para um texto que parecia tentar responder a uma tarefa que permaneceu pendente em Derrida, de uma pendência cada vez mais irresolúvel: pensar o legado de Walter Benjamin, ser digno dessa herança, ser capaz de assumi-la. Ao lado, à margem deste "não fui capaz de ler" com o qual Derrida fecha seu texto, eu acrescentaria interrogações que me parecem fazer mais justiça ao seu texto, pelo menos, que aquela que pôde fazer Derrida ao texto de Benjamin. Sabemos que na esteira da desmontagem da primazia metafísica do futuro presente em todo o pensamento sobre o porvir, desenvolve-se na obra de Derrida uma temática inspirada nas noções de promessa, do dom e da justiça por vir, figuras de um futuro já não redutível à presença. ${ }^{35} \mathrm{Em}$ toda essa elaboração, em todo o rigor de seu desenho, não chama a atenção a ausência quase absoluta de uma reflexão sobre o pensador moderno que mais incisiva e urgentemente vinculou a possibilidade mesma do pensamento e da práxis ao índice de uma redenção, à possibilidade de uma promessa que mantivesse a estreita abertura da porta do porvir? Não se sente ali a falta do pensador que mais radicalmente subtraiu a promessa à ditadura da presença, ao insistir desesperadamente na possibilidade de seu fracasso como promessa?

Na medida em que, para Derrida, a temática da promessa se vincula estreitamente com o pensamento do dom, com o doar, com a oferta, até que ponto a reflexão sobre esse dom a partir da temática heideggeriana do "haver enquanto doar" - ou seja, toda a insistência de Heidegger sobre a literalidade do es gibt - não sufoca e silencia, na leitura de Derrida, a referência benjaminiana ao já sido que nunca acedeu ao haver? Não haveria algo no pensamento benjaminiano sobre o dom - que em Benjamin é inseparável de uma reflexão sobre aquele que recebe, aquele que sabe escutar o murmúrio de tudo o que foi escravizado no passado - que complicaria essa redução?

Ao falar do entre-guerras Derrida recorre à noção de psique judaico-alemã. Mesmo com a ressalva de que 'psique' aqui não alude a uma suposta psicologia coletiva, não seria a denegação aí um índice de que se recorre aqui à idealização de um "espírito de época" no qual a recorrência de certos termos em alguns autores é reduzido, num 
raciocínio proléptico, a um antecipadamente confirmado anúncio do que viria. Ao aludir, por exemplo, aos calafrios que, "quando se pensa nas câmaras de gás e nos fornos crematórios", teríamos ao ver, no texto benjaminiano de 1921, a menção a uma exterminação "sem sangue", ou seja, ao arrancar a figura de tal destruição de seu papel no texto benjaminiano e justapô-lo ao Holocausto, não estaríamos optando por não ler o que disse Benjamin sobre o Nazismo? Não só o que disse explicitamente nos textos posteriores, mas também o que anunciou em "Para a crítica da violência", um ensaio dedicado, ao fim e ao cabo, a pensar as condições de possibilidade da violência?

Quais são as condições de possibilidade da elisão de tudo isso em Jerusalém, em 1988, no congresso onde não pôde entrar o palestino? Em "Interpretações em guerra" teriam a alegorização nacional da figura do alemão e do judeu na "psique judaico-alemã" ou a alegorização nacional das figuras do grego e do judeu em Força de lei-que Derrida localiza em um ensaio benjaminiano onde estas duas palavras não aparecem - algo a ver com o palestino que não pôde aceder ao espaço no qual falou Derrida? Teria algo a ver com a impossibilidade de nomear essa figura, essa nacionalidade irrepresentável, esse exterior a todo Estado? Seria o palestino o lá-fora constitutivo do judeu e do grego, tal como invocados por Derrida na leitura de um texto onde não aparecem estas palavras? Ao rotular como "judaica" e "grega" as violências divina e mítica que teoriza Benjamin, não estaria Derrida sub-titulando seu ensaio, implicitamente, "Como não ler o Holacausto na Intifada"? Como, ao se perguntar por aquilo que 1921 teria antecipado de 1941, cegarse ante o que 1921 lhe reclama, lhe demanda a 1988 ?

A pergunta não me parece injusta com o texto de Derrida. Para usar uma expressão cara a ele, não se trata de um exemplo entre outros, o exemplo da violência das forças de ocupação. Trata-se da manifestação contemporânea paradigmática do que Benjamin chamaria a violência da legalidade que continuamente ignora suas próprias leis, já que ela está dotada da prerrogativa de redefinir continuamente os limites da própria lei. Esta seria, para o Benjamin do ensaio de 1921, a caracterização da violência policial, militarista, a violência que suspende a distinção entre a manutenção da lei e a instalação da lei, já que ela pode impor uma nova legalidade cada vez que transgride os limites da legalidade constituída. Não assistimos hoje a manifestação desta suspensão completa da dicotomia entre manutenção e instalação da lei na conversão do império em permanente 
máquina de guerra que opera fora de toda lei prévia, que cria uma nova lei a cada ato repressivo? Se para essa conversão, Jerusalém não é uma cidade entre outras e a população palestina não é uma vítima entre outras, não poderíamos aventurar a hipótese de que cegar-se ante o texto de Benjamin, recusar-se a lê-lo, ou lê-lo distorcido por uma lente heideggeriana - em outras palavras, não ser digno da tarefa dessa herança - não seria, de nenhuma maneira, uma omissão ou uma distorção entre outras, e sim o nome da nossa derrota?

Abstract: This article analyzes Walter Benjamin's classic Zur Kritik der Gewalt in the light of an important moment of its critical fortune, Jacques Derrida's Force de loi . First I question Derrida's association between Benjamin's essay and a presumed "antiparliamentarian wave" in Weimar thought. I then examine Derrida's identification of the Benjaminian notion of divine violence with the concept of Destruktion elaborated by Heidegger a few years later. I conclude with some consideration of the links between the reading of Benjamin proposed in Force of loi and the postulates of another Derrida essay, "Interpretations at War," presented in a 1988 colloquium in Jerusalem, held during the second Intifada and marked by the absence of Palestinian guests.

Keywords: Violence. Palestine. Deconstruction. Benjamin, Walter. Derrida, Jacques. Heidegger, Martin.

\section{Referências Bibliográficas}

AVELAR, Idelber. The Letter of Violence: Essays on Narrative, Ethics, and Politics. New York: Palgrave, 2004.

BENJAMIN, Walter. Zur Kritik der Gewalt. In: BENJAMIN, Walter. Gesammelte Shriften II-1. Frankfurt am Main: Suhrkamp, 1997, p. 179-203.

BULLOCK, Marcus; JENNINGS, Michael W. Chronology 1892-1926. In: BENJAMIN, Walter. Selected Writings. Vol. 1:1913-1926. Cambridge, Mass. e Londres: Harvard UP, 1996, p. 490-515. 
DERRIDA, Jacques. Force de loi: Le “fondement mystique de l'autorité". Paris: Galilée, 1994.

DERRIDA, Jacques. Interpretations at War: Kant, the Jew, the German (1991). In: DERRIDA, Jacques. Acts of Religion. ed. por Gil Anidjar. London: Routledge, 2002.

DERRIDA, Jacques. Limited inc. Baltimore: Johns Hopkins University Press, 1977.

DERRIDA, Jacques. Spectres de Marx: l'état de la dette, le travail du deuil et la nouvelle Internationale. Paris: Galilée, 1993.

SOREL, Georges. Reflexions sur la violence. 1908. Paris: M. Rivière et Cie., 1972.

\section{Notas}


${ }^{1}$ Agradeço a Ana Maria Gonçalves a revisão cuidadosa de uma versão anterior deste artigo.

${ }^{2}$ Jacques Derrida, Force de loi: Le "fondement mystique de l'autorité". Paris: Galilée, 1994. São de minha autoria todas as traduções de fontes citadas em outras línguas.

${ }^{3}$ AVELAR, Idelber. The Letter of Violence: Essays on Narrative, Ethics, and Politics. New York: Palgrave, 2004.

${ }^{4}$ BENJAMIN, Walter. Zur Kritik der Gewalt. In: BENJAMIN, Walter. Gesammelte Shriften II-1. Frankfurt am Main: Suhrkamp, 1997, p. 179-203.

${ }^{5}$ Ao escrever esse texto Walter Benjamin já havia composto alguns de seus ensaios juvenis mais ilustres, "Sobre a linguagem em geral e a linguagem dos homens" (1916), "Sobre o programa da filosofia vindoura" (1917) e a tese doutoral publicada em 1920 sobre $O$ conceito de crítica no romantismo alemão. O ensaio sobre a violência dá testemunho da tentativa de integrar as incursões anteriores na filosofia da linguagem às recém-despertas preocupações políticas. Para uma boa cronologia dessa época da vida de Benjamin, ver BULLOCK; JENNINGS. Chronology 1892-1926, p. 490-515.

${ }^{6}$ Georges Sorel, Reflexions sur la violence. 1908. Paris: M. Riviere et Cie., 1972.

${ }^{7}$ BENJAMIN. Zur Kritik der Gewalt, p. 180.

${ }^{8}$ BENJAMIN. Zur Kritik der Gewalt, p. 180.

${ }^{9}$ BENJAMIN. Zur Kritik der Gewalt, p. 181.

${ }^{10}$ BENJAMIN. Zur Kritik der Gewalt, p. 181-182.

${ }^{11}$ BENJAMIN. Zur Kritik der Gewalt, p. 184.

${ }^{12}$ DERRIDA. Force de loi, p. 146.

${ }^{13}$ BENJAMIN. Zur Kritik der Gewalt, p. 186.

${ }^{14}$ BENJAMIN. Zur Kritik der Gewalt, p. 189.

${ }^{15}$ BENJAMIN. Zur Kritik der Gewalt, p. 189.

${ }^{16}$ BENJAMIN. Zur Kritik der Gewalt, p. 189.

${ }^{17}$ Jacques Derrida, Spectres de Marx: l'état de la dette, le travail du deuil et la nouvelle Internationale. Paris: Galilée, 1993. Sobre Espectros de Marx, ver o belo artigo de Fredric Jameson, "Marx's Purloined Letter." New Left Review 209: (1995), p. 75-109. Ver também o meu "Marx, en inminencia y urgencia." Revista de Crítica Cultural 11 (1995), p. 63-66.

${ }^{18}$ DERRIDA. Force de loi, p. 69.

${ }^{19}$ BENJAMIN. Zur Kritik der Gewalt, p. 191.

${ }^{20}$ BENJAMIN. Zur Kritik der Gewalt, p. 199.

${ }^{21}$ DERRIDA. Force de loi, p. 79.

${ }^{22}$ DERRIDA. Force de loi, p. 70.

${ }^{23}$ DERRIDA. Force de loi, p. 69.

${ }^{24}$ DERRIDA. Force de loi, p. 67-68.

${ }^{25}$ DERRIDA, Jacques. Interpretations at War: Kant, the Jew, the German (1991). In: DERRIDA, Jacques. Acts of Religion. ed. por Gil Anidjar. London: Routledge, 2002.

${ }^{26}$ DERRIDA. Force de loi, p. 73.

${ }^{27}$ DERRIDA. Force de loi, p. 73.

${ }^{28}$ DERRIDA. Force de loi, p. 73.

${ }^{29}$ DERRIDA. Force de loi, p. 73.

${ }^{30}$ Ver DERRIDA, Jacques. Limited inc. Baltimore: Johns Hopkins University Press, 1977.

${ }^{31}$ DERRIDA. Force de loi, p. 139-140.

${ }^{32}$ DERRIDA. Force de loi, p. 142-143.

${ }^{33}$ DERRIDA. Force de loi, p. 146.

${ }^{34}$ DERRIDA. Force de loi, p. 146.

${ }^{35}$ Listar todas as obras derridianas em que se desenvolve essa temática exigiria praticamente um elenco completo de suas publicações das últimas décadas de sua vida, mas como marcos incontornáveis, consulte-se: Donner le Temps. 1. La Fausse Monnaie. Paris: Galilée, 1992. Politiques de l'amitié, Paris: Galilée. 1994. De l'hospitalité. Paris: Calmann-Lévy,1998. 